\title{
Utilización del antibiotipo como marcador epidemiológico en infecciones intrahospitalarias: Comparación con la epidemiología molecular
}

JAIME LABARCA L.*

\begin{abstract}
ANTIBIOTYPE UTILIZATION AS AN EPIDEMIOLOGICAL MARKER IN NOSOCOMIAL INFECTIONS: COMPARISON WITH MOLECULAR EPIDEMIOLOGY
\end{abstract}

Key words: Molecular epidemiology, Genotyping, Antibiotyping.

\section{INTRODUCCIÓN}

Una de las preguntas más frecuentes para los epidemiólogos, clínicos y microbiólogos es saber si dos bacterias son iguales o diferentes, o sea, la evaluación de clonalidad. Hay múltiples herramientas para responder esta pregunta, tanto desde el punto de vista fenotípico, como genotípico; sin embargo, sólo pocas de ellas se utilizan en la práctica y habitualmente esta pregunta queda sin respuesta. Las técnicas empleadas con mayor frecuencia para evaluar clonalidad se muestran en la Tabla 1. Generalmente la primera aproximación para evaluar un origen clonal común entre dos bacterias está dada por las características fenotípicas de ellas mismas, entre las cuales el perfil de susceptibilidad a los antimicrobianos o antibiotipo es el más usado. Por otro lado, el gold standard para evaluar clonalidad está dado por las técnicas de tipificación molecular, las que tienen entre sí algunas diferencias en cuanto a discriminación y reproducibilidad. La pregunta planteada consiste en evaluar la correlación que hay entre el antibiotipo y el gold standard, que serían las técnicas de tipificación molecular.

\section{Técnicas de tipificación molecular}

Con el pasar de los años las técnicas de tipificación molecular bacteriana están siendo cada vez más disponibles. En la década de los 90 nuevas técnicas han pasado a liderar el campo de la epidemiología molecular, siendo cada vez más discriminatorias y reproducibles. Entre ellas destacan en el mundo y en Chile las técnicas basadas en RPC y en electroforesis en gel de campo pulsado (PFGE); sin embargo, hay una variedad de técnicas disponibles las cuales pueden ser de elección frente a patógenos específicos. ${ }^{1}$ Si bien la secuenciación puede ser la técnica que discrimine finalmente si dos bacterias son clonadas o no, esta técnica está todavía en investigación y su uso no es rutinario. Por otro lado, la PFGE, que nos permite evaluar la mayor parte del ADN cromosomal, es hoy en día la técnica que tiene el mejor poder discriminatorio y la mejor reproducibilidad, además de que permite tipificar la mayor cantidad de especies bacterianas. Los métodos basados en RPC tienen la ventaja de ser más rápidos, más económicos y requerir infraestructura que está más ampliamente disponible; sin embargo,

\footnotetext{
* Departamento de Medicina, Hospital Clínico, Pontificia Universidad Católica de Chile.
} 
dan información de un sector reducido del ADN cromosomal de las bacterias y son menos reproducibles. $^{1}$

\section{Cómo, cuándo y para qué evaluar la clonalidad}

Como se mencionó anteriormente hay múltiples herramientas, tanto fenotípicas como genotípicas, para evaluar clonalidad; sin embargo, la más usada entre las fenotípicas es el antibiotipo, y las técnicas basadas en RPC y PFGE entre las genotípicas (Tabla 1). Las otras técnicas genotípicas, así como las fenotípicas, tienen su principal indicación frente a casos particulares.

Las situaciones en las que es necesario aproximarse a la clonalidad pueden ser múltiples; sin embargo, desde el punto de vista clínico, las más comunes son para discriminar infección versus contaminación, como por ejemplo el caso de la bacteremia causada por múltiples cepas de Staphylococcus coagulasa negativa. También puede ser necesario evaluar el origen clonal frente a infecciones recurrentes y así discriminar entre re-infección por la misma cepa o infección nueva por una cepa distinta. Esto es especialmente crítico en el caso de pacientes con infecciones relacionadas a material protésico. Desde el punto de vista microbiológico, también hay múltiples circunstancias en las cuales aparece la pregunta respecto de la clonalidad, por ejemplo cuando aparecen cepas de una especie con diferentes características fenotípicas, ya sean morfológicas, de biotipo o de susceptibilidad, en una muestra clínica, o por el contrario, cuando aparecen cepas con carac- terísticas fenotípicas similares en distintas muestras o provenientes de distintos pacientes.

En el área epidemiológica se dan las situaciones más comunes en las que es necesario evaluar clonalidad con los mejores métodos disponibles; esto sucede en el estudio de brotes intra o extrahospitalarios y también cuando se quiere demostrar diferentes mecanismos de transmisión de bacterias, que no necesariamente constituyen un brote.

Con la información del origen clonal, el médico clínico, microbiólogo o epidemiólogo puede tomar conductas terapéuticas, de laboratorio, o de intervención, sólidamente fundamentadas en el resultado de estos estudios.

\section{Correlación entre antibiotipo y tipificación molecular}

Para la evaluación de clonalidad a partir del antibiograma no hay una metodología específica común a todas las especies bacterianas, así como tampoco hay herramientas generales que se puedan aplicar a grupos comunes de especies bacterianas. Cada situación es única y requiere de un análisis específico. Sin embargo, para que este análisis sea apropiado se deben considerar los siguientes aspectos:

- el genotipo bacteriano es dinámico. Va cambiando a través del tiempo y una cierta cantidad de mutaciones en un período determinado es esperable en la vida de una cepa bacteriana ${ }^{1}$

- la susceptibilidad de una bacteria a través del tiempo es un fenómeno dinámico. Es conocido que las bacterias pueden cambiar

Tabla 1. Métodos de tipificación bacteriana

\begin{tabular}{ll}
\hline Métodos fenotípicos & Métodos genotípicos \\
\hline Biotipificación & Análisis plasmidial \\
Antibiotipo & REA ADN cromosomal \\
Serotipificación & RFLP usando sondas de ADN \\
Bacteriófago & Ribotipificación \\
Western blot & PFGE \\
Electroforesis de multilocus enzimático & RPC \\
Secuenciación & \\
\hline
\end{tabular}

\section{S 158}


el perfil de susceptibilidad, e incluso pueden generar resistencia intratramiento. Esto puede ocurrir por múltiples motivos, desde desrepresión de genes reprimidos, hasta ganancia de genes de resistencia, por adquisición de plasmidios o de transposones. ${ }^{2,3}$

Por lo tanto, para una mejor interpretación del antibiotipo y evaluar la posibilidad de clonalidad se hace necesario conocer:

- la epidemiología (frecuencia y distribución) de los microorganismos, ya que organismos de muy baja frecuencia en un área determinada generalmente apoyan la clonalidad

- la susceptibilidad esperada de los microorganismos, dado que cada especie bacteriana tiene un perfil de susceptibilidad particular en un área determinada. Por ejemplo, Acinetobacter baumannii en un centro asistencial puede ser resistente a sulbactam/ ampicilina, en cambio en otro centro puede ser habitualmente sensible

- los mecanismos de resistencia, ya que aquellas bacterias que tienen genes de resistencia de origen plasmidial pueden cambiar con más facilidad el perfil de resistencia que aquellos con genes de resistencia de origen cromosomal

- la genética del microorganismo, por ejemplo la diseminación de un microorganismo de un hospital a otro, puede corresponder a la diseminación de pocos clones, como lo es el caso de Staphylococcus aureus resistente a cloxacilina, comparando con otras especies (bacilos Gram negativos) que pueden corresponder a la diseminación de distintos clones. Sin embargo, hay algunos elementos que permiten apoyar el concepto de origen clonal. Por ejemplo, microorganismos de baja ocurrencia con fenotipo especial, independientemente del antibiograma (Ej.: Ochrobactium anthropi). También apoya una clonalidad si es más infrecuente el perfil de resistencia que presenta una bacteria determinada (Ej.: Escherichia coli multiresistente). Por otro lado, no apoya una clonalidad la coexistencia de antibiotipos diferentes en una especie bacteriana que se aisla frecuentemente (E.coli, Pseudomonas aeruginosa). Algunas especies bacterianas tienen intrínsecamente perfil de multiresistencia, esperable en estas bacterias, pero no necesariamente implican un mismo perfil genotípico (SAMR, A. baumannii, Stenotrophomona maltophilia). En suma, lo importante es buscar los marcadores que permitan discriminar mejor la posibilidad de este origen genético común.

\section{El antibiograma cuantitativo. Aproximación a la determinación de clonalidad a partir del antibiograma}

Una manera de optimizar el antibiotipo para evaluar la relación clonal entre dos bacterias está dada por el antibiograma cuantitativo. Consiste en análisis más acucioso de las diferencias de susceptibilidad entre dos aislamientos bacterianos, con el fin de aproximarse a la clonalidad. Este método utiliza la comparación de los diámetros de los halos de inhibición en la técnica de difusión del disco (Kirby Bauer). En general se escogen los antimicrobianos que tengan una mayor variación para la cepa en estudio, de tal manera que permita una mejor discriminación. Se evalúa el resultado de la sumatoria de los halos de inhibición de un aislamiento bacteriano y se compara con el otro aislamiento. Esto se hace mediante la aplicación de una fórmula matemática de la cual se desprende un coeficiente de similaridad para los dos aislamientos bacterianos que se están comparando. El coeficiente similaridad se obtiene a través de la fórmula para calcular la distancia euclidiana: $E_{j k}=\sqrt{ } \sum\left(\mathrm{x}_{\mathrm{ij}}-\mathrm{x}_{\mathrm{ik}}\right)^{2}$, donde $\mathrm{x}_{\mathrm{ij}}-\mathrm{y} \mathrm{x}_{\mathrm{ikk}}$ son los valores de los diámetros de inhibición de un antimicrobiano dado $i$ para dos distintos aislamientos $j$ y $k .^{4} \mathrm{~A}$ más bajo el valor del coeficiente de similaridad, es mayor la similaridad entre dos cepas bacterianas. Los valores de coeficiente de similaridad obtenidos al comparar dos cepas, se pueden correlacionar con los resultados obtenidos al comparar los aislamientos por técnicas de tipificación molecular. Esto permite para la especie bacteriana en estudio, usando los antimicrobianos seleccionados, establecer un punto de corte que se relaciona con clonalidad o no clonalidad.

Esto ha podido ser aplicado por ejemplo al estudio de bacteremia por S. coagulasa negativa, cuando hay dos hemocultivos positivos. La clonalidad entre estas dos cepas orientaría a 
una verdadera infección en cambio; el ser no clonales orientaría a una contaminación. En un estudio clínico (datos no publicados), al evaluar todos los episodios (17/17) asociados con cepas de $\mathrm{S}$. coagulasa negativa con patrón idéntico mediante PFGE, se obtuvo coeficientes de similaridad $<10(X=3,51)$ al usar el antibiograma cuantitativo. La mayoría de los episodios (4/6) asociados con cepas con diferente patrón de PFGE tuvieron antibiograma cuantitativo con coeficiente de similaridad de 19 o mayor $(\mathrm{X}=$ 20,52). En general se logró una correlación $91 \%(21 / 23)$ entre estas dos técnicas.

\section{CONCLUSIONES}

El antibiotipo sigue siendo válido como la primera aproximación al origen clonal al comparar dos aislamientos bacterianos, y muchas veces es posible aproximarse a la clonalidad de las cepas a partir del antibiotipo, usando el antibiograma habitual. Para tener una buena aproximación siempre se debe considerar la epidemiología del microorganismo, la genética bacteriana, los perfiles de susceptibilidad habituales y los mecanismos moleculares de resistencia involucrados. Finalmente es importante saber identificar en el perfil de susceptibilidad, un buen marcador que permita aproximarse a la clonalidad entre aislamientos bacterianos.

\section{BIBLIOGRAFÍA}

1.- TENOVER F C, ARBEIT R D, GOERING R V et al. Interpreting chromosomal DNA restriction patterns produced by pulsed-field gel electrophoresis: criteria for bacterial strain typing. J Clin Microbiol 1995; 33 (9): 2233-9.

2.- JOHN J F, RICE L B. The microbial genetics of antibiotic cycling. Infect Control Hosp Epidemiol 2000; Jan; 21 (1 Suppl): S22-S31.

3.- MCGOWAN J E. Strategies for study the role of cycling on antimicrobial use and resistance. Infect Control Hosp Epidemiol 2000; 21 (1 Suppl): S36-S43.

4.- BLANC D S, PETIGNAT C, MOREILLON P, WENGER A, BILLE J, FRANCIOLI P. Quantitative antibiogram as a typing method for the prospective epidemiological surveillance and control of MRSA: comparison with molecular typing. Infect Control Hosp Epidemiol 1996 Oct.; 17 (10): 654-69.

Correspondencia a:

Jaime Labarca Labarca

E-mail:jlabarca@med.puc.cl 